\title{
TEST RESULTS OF NB3SN RIBBONS FOR THE PRINCETON D COIL TEST PROGRAM
}

BY

J. KAUGERTS, J, FILE AND

J. W. WILLARD

\section{PLASMA PHYSICS LABORATORY}

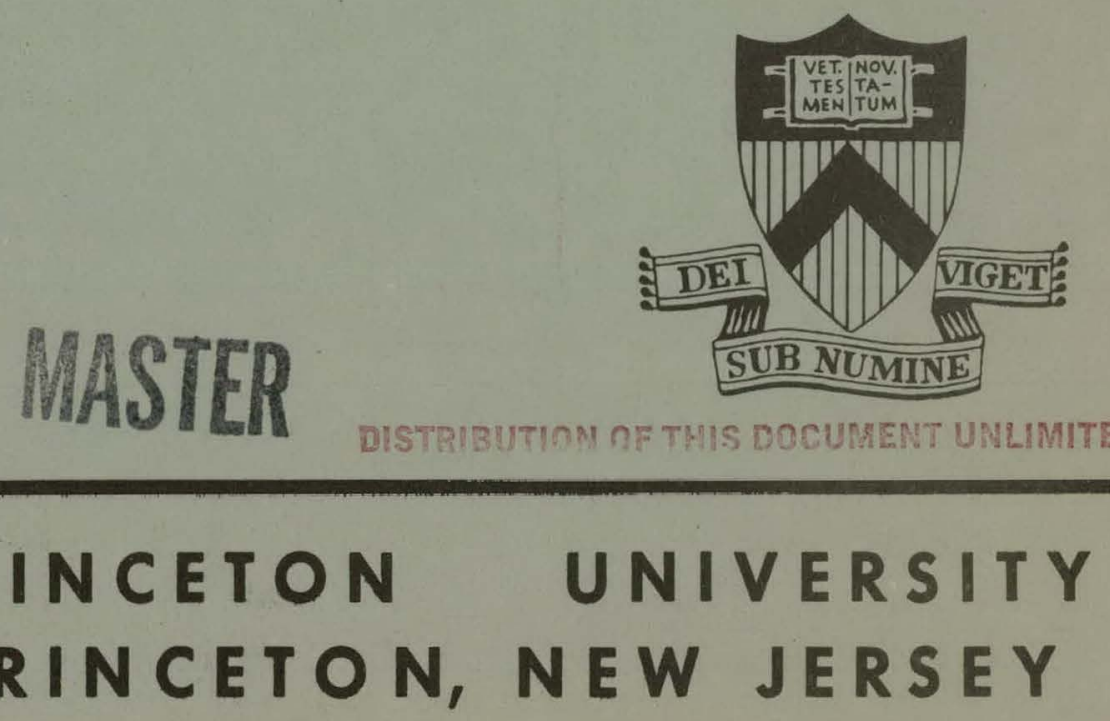




\section{DISCLAIMER}

This report was prepared as an account of work sponsored by an agency of the United States Government. Neither the United States Government nor any agency Thereof, nor any of their employees, makes any warranty, express or implied, or assumes any legal liability or responsibility for the accuracy, completeness, or usefulness of any information, apparatus, product, or process disclosed, or represents that its use would not infringe privately owned rights. Reference herein to any specific commercial product, process, or service by trade name, trademark, manufacturer, or otherwise does not necessarily constitute or imply its endorsement, recommendation, or favoring by the United States Government or any agency thereof. The views and opinions of authors expressed herein do not necessarily state or reflect those of the United States Government or any agency thereof. 


\section{DISCLAIMER}

Portions of this document may be illegible in electronic image products. Images are produced from the best available original document. 
TEST RESULTS OF NB 3 SN RIBBONS FOR THE PRINCETON D COIL TEST PROGRAM

J. Kaugerts*, J. File, J. W. Willard

ABSTRACT

A previously described $D$ coll test program has been modified. Details of a smaller $\mathrm{Nb}_{3} \mathrm{Sn} \mathrm{D} \operatorname{coll}$ test program are described. Cusp coil tests have been made with several $\mathrm{Nb}_{3} \mathrm{Sn}-\mathrm{NbTi}$ hybrid field coils. Measurements of both the quench and recovery currents as a function of magnetic field component perpendicular to the wide edge of the ribbon are presented.

\section{INTRODUCTION}

In recent months there has been a proliferation of projected plasma research devices and proposed fusion reactors recommending the use of a $D$ or modified D coils. Some of the devices proposing such coils are: The Princeton Fusion Reactor Reference Design ${ }^{1}$, the University of Wisconsin Fusion Reactor Reference Design ${ }^{2}$, the Joint European Trokamak $^{3}$, and others. Tt. has been shown previouslyl that high fields up to $160 \mathrm{kG}$, may be extremely useful in fusion power reactors as well as advanced plasma physics experimental devices. The objective of this program is to develup reliable high field superconducting magnets for these toroidal devices.

The $D$ shape is unique to a particular current filament in a toroidal field. The shape depends on its location in a bundle, and the magnetic field at that point. File et $a 1^{4}$, previously have shown that this kind of coil, which partially accommodates the large forces generated by high magnetic fields, will be stable if it is in pure tension, and therefore not subject to any bending moments. It is interesting to note that not only does this result in a system of minimum stress, but also one of maximum stored energy ${ }^{5}$, a property that may be useful to those engaged in research in that field.

Later, it was pointed out by File and Sheffield ${ }^{6}$, that a torus of $\mathrm{N}$ cuils, has $\mathrm{T}$ different shaped $\mathrm{D}$ 's ' if each turn $T$ is to be in pure tension. Further, the straight stem of the $D$ must also be modified, for the reason described below.

A previously described $D$ coil test program ${ }^{7}$ has been considerably modified and details of the smaller $\mathrm{Nb}_{3} \mathrm{Sn} D$ coil test program are described. In addition test results on $\mathrm{Nb}_{3} \mathrm{Sn}$ ribbons to be used in the manufacture of the hybrid superconducting background coils for the smaller $\mathrm{D}$ coil are preserted in section III.

\section{D COIL TEST FACTLITY}

We are examining the engineering compromise that must be made in order to take maximum advantage of constant lension coils in toroidal magnete. For example, we have found that winding techniques are greatly enhanced by adding a s.light curvature to the straight stem of the $D$. The stem, instead of being straight, is an arc of constant curvature, tangent to the $D$ and of $f-$ set at the centerline of the $D$ by about 1 or $2 \%$ of the

tanuscript received Seprember 30, 1974.

This work was supported by U. S. Atomic Energy Commission Contract AT(11-1)-3073 2nd by Electric Power Research Institute Contract RP113.

* Princeton University Plasma Physics Laboratory P. O. Box 451, Princeton, N. J. 08540 horizontal diameter, see Fig. 1. The effects of this curvature and other engineering compromises on the constant tension configurations are being studied and will be reported later.

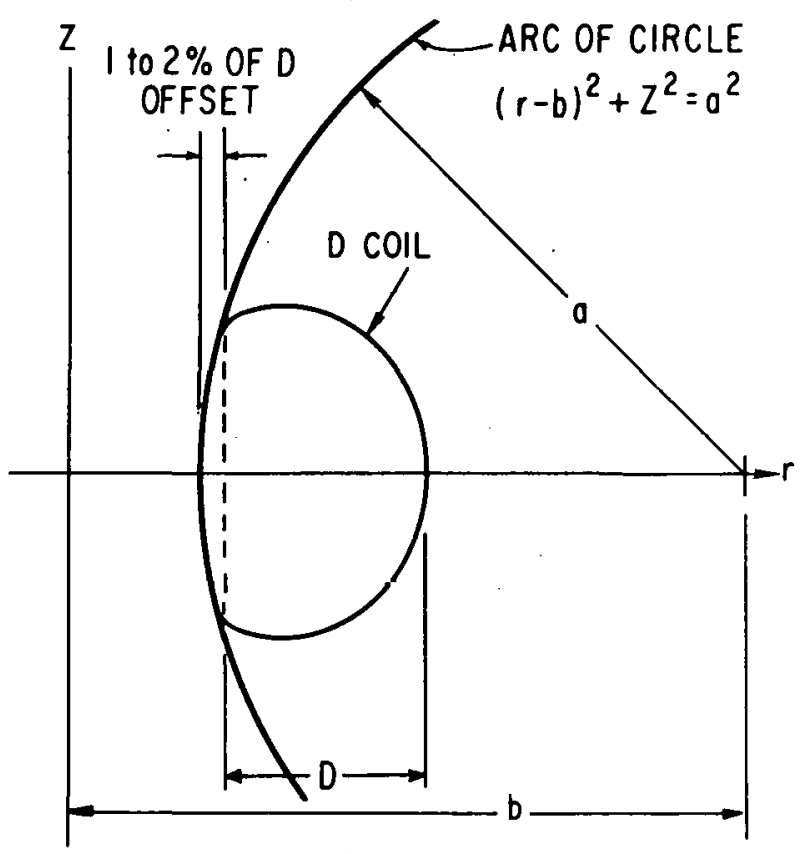

Fig. 1 "D" Coil Parameters

The previously described $100 \mathrm{kG}$ test facility ${ }^{7}$ utilized six background coils and a $D$ shaped test coil. We now plan to test a smaller $D$ cril in a modified test stand consisting of two hybrid $\mathrm{Nb}_{3} \mathrm{Sn}-\mathrm{NbTi}$ coils previously called the auxiliary coils. The design specifications of these coils are shown in Fig. 2 and Table I. The $\mathrm{Nb}_{3} \mathrm{Sn}$ portions of the coils are wound in pancake fashion using $1 / 2 \mathrm{~cm}$ wide 200 ampere tape. The $\mathrm{NbTi}$ coils are wound in an integral coil form with the $\mathrm{Nb}_{3} \mathrm{Sn}$ windings. The $\mathrm{NbTi}$ coils are layer wound from multifilament composite conductor $.254 \times .342 \mathrm{~cm}$ in cross-section.

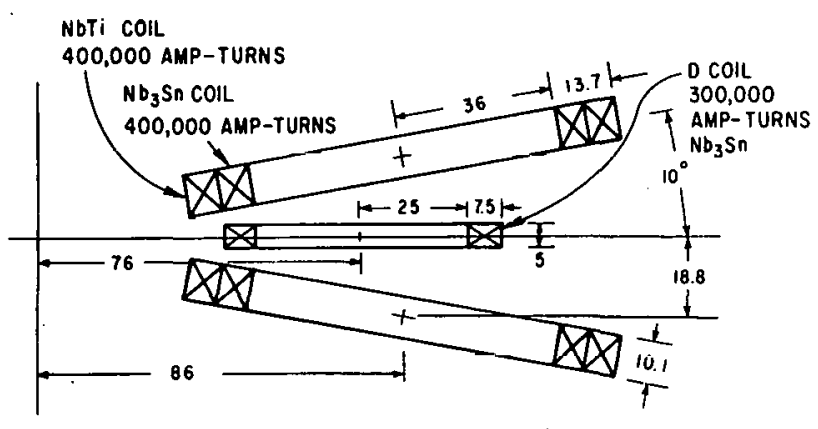

DIMENSIONS IN CENTIMETERS

Fig. 2 Test Stand Coil Śpecifications 


\begin{tabular}{|c|c|c|c|}
\hline & D coil & $\begin{array}{l}\text { Hybrid } \mathrm{Nb}_{3} \mathrm{Sn} \\
\text { Section }\end{array}$ & $\begin{array}{l}\text { Hybrid Nori } \\
\text { Section }\end{array}$ \\
\hline Antpere Turns & 300,000 & 400,000 & 400,000 \\
\hline $\begin{array}{l}\text { Overall Current } \\
\text { Density }\end{array}$ & $7895 \mathrm{Acm}^{2}$ & $6200 \mathrm{~A} / \mathrm{cm}^{2}$ & $6800 \mathrm{~A} / \mathrm{cm}^{2}$ \\
\hline Number of Turns & 4300 & 2030 & 494 \\
\hline Winding Type & layer & Pancake & Layer \\
\hline $\begin{array}{l}\text { Maximum Total } \\
\text { Field. }\end{array}$ & $40.7 \mathrm{k} 0 \mathrm{e}$ & $35.4 \mathrm{kOe}$ & 31.1600 \\
\hline $\begin{array}{l}\text { Operating } \\
\text { current }\end{array}$ & $80 \mathrm{~A}$ & 197A & 809 \\
\hline Insulation & $6.4 \times 10^{-4} \mathrm{~cm}$ mylar & $1.27 \times 10^{-3} \mathrm{~cm}$ mylar & $\begin{array}{l}\text { Slotted G-10 } \\
\text { and mylar }\end{array}$ \\
\hline $\begin{array}{l}\text { Conductor } \\
\text { Dimensions }\end{array}$ & $\begin{array}{l}.23 \mathrm{~cm} \text { wide, } \\
.015 \mathrm{~cm} \text { Thk, } \\
.005 \mathrm{rm} \text { stn Stl, } \\
.010 \mathrm{~cm} \text { cu. }\end{array}$ & $\begin{array}{lll}\text { area } & 1 & .5 \mathrm{cmr} x .053 \mathrm{~cm} \\
\text { area } & 2 & .5 \mathrm{~cm} \times .050 \mathrm{~cm} \\
\text { area } & 3 & .5 \mathrm{~cm} x .045 \mathrm{~cm}\end{array}$ & $.2540 \pi \times .3430 \mathrm{~m}$ \\
\hline
\end{tabular}

In Fig. 3 we show a plot of the BR product of the smaller D coil in the present test stand. Shown for comparison is the $B R$ product of twenty similar $D$ coils arranged in a toroidal fashion.

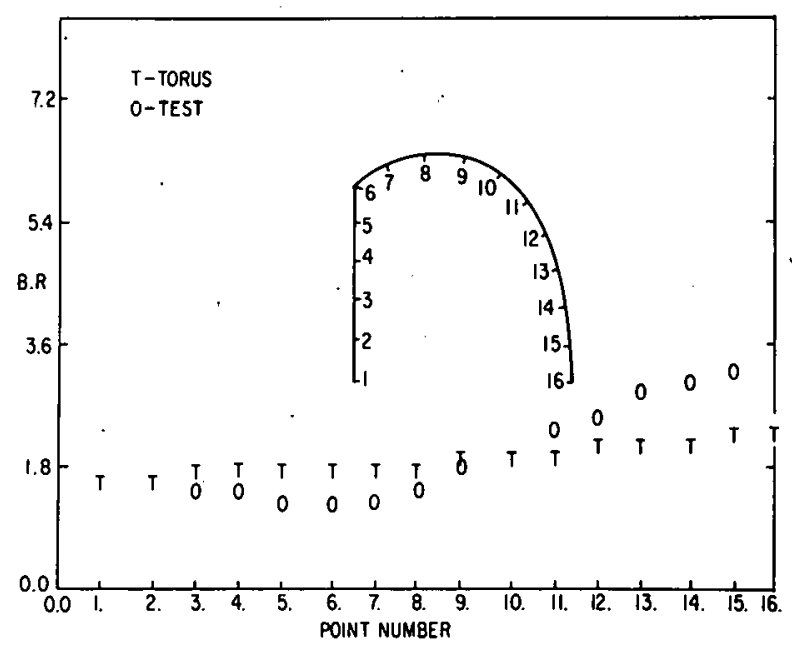

Fig. 3 BR Product vs Position around " $D$ " Coil

The proposed D coil is layer wound from old RCA SR2100 marerial in a manner similar to the coil used in the Princeton FM-1 machine ${ }^{8}$. The. coil will contain 4300 turns of $0.23 \mathrm{~cm}$ wide copper clad $\mathrm{Nb}_{3} \mathrm{Sn}$ ribbon which carries a current of 80 amperes. The coil is wound in a modified constant tension configuration with a major and minor diameter of $77 . .5$ and $64 \mathrm{~cm}$. The minor cross-section of the coil is $5 \times 7.6 \mathrm{~cm}$. When energized in the test stand a maximum total field of $35.7 \mathrm{kOe}$ is reached in the test coil. The maximum radial field at the conductor is $10.1 \mathrm{kOe}$.
Several $\mathrm{Nb}_{3} \mathrm{Sn}$ composite ribbons, originally obtained for the construction of the $100 \mathrm{kG} \mathrm{Nb}{ }_{3} \mathrm{Sn}-\mathrm{NbTi}$ hybrid test stand, are to be used for the modified test stand described above. Ribbon dimensions and configuration, as well as the maximum magnetic field $H_{1}$ perpendicular to the broad face of the ribbon and its accompanying parallel fleld component $\mathrm{H}_{11}$ are given in. Table II.

TABLE II

$\mathrm{Nb}_{3}$ Sn Ribbon* Properties

\begin{tabular}{|c|c|c|c|c|c|}
\hline $\begin{array}{l}\text { arrent } \\
\text { Pating + } \\
\text { (amps) }\end{array}$ & $\begin{array}{l}\text { Copper } \\
\text { Thichess } \\
\left(10^{-3} \mathrm{~cm}\right)\end{array}$ & $\begin{array}{c}\text { Stainless Steel } \\
\text { Thickness } \\
\left(10^{-3} \mathrm{~cm}\right)\end{array}$ & $\begin{array}{l}\quad \text { Total } \\
\text { Thickpess } \\
\left(10^{-3} \mathrm{~cm}\right)\end{array}$ & $\begin{array}{l}\text { Max. Perp; } \\
\text { field, } \mathrm{H} 1 \\
\text { (xoe) }\end{array}$ & $\begin{array}{l}\text { Parallel } \\
\text { field } \mathrm{H}_{11} \\
\text { (KOe) }\end{array}$ \\
\hline 200 & 25 & 19 & 51 & 43 & 65 \\
\hline 220 & 20 & 21 & 18 & 25 & 75 \\
\hline 200 & 15 & 21 & 43 & 20 & 78 \\
\hline
\end{tabular}

- $0.5 \mathrm{can}$ wide $\mathrm{N}_{3} \mathrm{Sn}$ composite ribuon supplied by Intermagnetics General corp.

tarrent at $100 \times 0$ parailel field

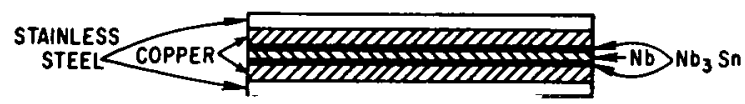

Since the $\mathrm{Nb}_{3} \mathrm{Sn}$ ribbons are to be operated in a dynamically rather than cryogenically stabilized mode there was concern that the large magnetic field component $\mathrm{H}_{1}$ might result in flux jumps which could drive the superconductor normal. To investigate this possibllity, we performed cusp coil tests with two of these materials having the least and most stabilizing copper. The behavior of the other material can be easily approximated by interpolation. One would like to simulate the typical magnetic and thermal environment that the superconductor will encounter in the full size magnet. In the cusp coil tests the superconductor sees mainly a perpendicular component of the magnetic field whereas in the test stand the superconductor ribbon is immersed in a field that includes a large parallel component. The magnetic field at which flux jumps occur varies inversely with critical current density $J$ of the diamagnetic shielding current in the superconductor. The collapse of this current and subsequent entry of magnetic field during a flux jump results in heating that can drive the superconductor normal. Since J decreases with increasing total magnetic field, the presence of an additional parallel magnetic field component raises the field at which flux jumps occur above that for the case of only a perpendicular magnetic field component present. If, during the cusp coil.tests, no flux jumps that drive the superconductor normal occur at flelds up to the design maximum perpendicular magnetic field, the material is considered to be flux jump stable in the full size magnet. If a flux jump does occur in this range, we must then consider the presence of the additional parallel field and examine the possibility that it will move the flux jump to a.higher perpendicular field than is actually displayed.

\section{Experimental Procedure}

The experimental configuration is shown in Fig. 4. The cusp coil consists of two pancake wound coils, series connected in such a way that the self-magnetic field profile between them has the shape of a cusp. An external field coil provides the large magnetic field component perpendicular to the broad ribbon 
surface. Each of the pancake coils is equipped with a nichrome wire heater, irstalled in the middle of the pancakes. The heater is used to remove remanent magnetization from the $\mathrm{Nb}_{3} \mathrm{Sn}$ as well as to create a normal region during the recovery current tests which will be described later. In addition, each pancake has a thin wafer-type Hall probe (Aerospace Controls, Inc. type HA-12) mounted flush with the top of the ribbon. The Hall probe is used to indicate flux jumps as well as the absence of remanent magnetization. The latter is done to assure the virgin magnetization state for the quench tests.

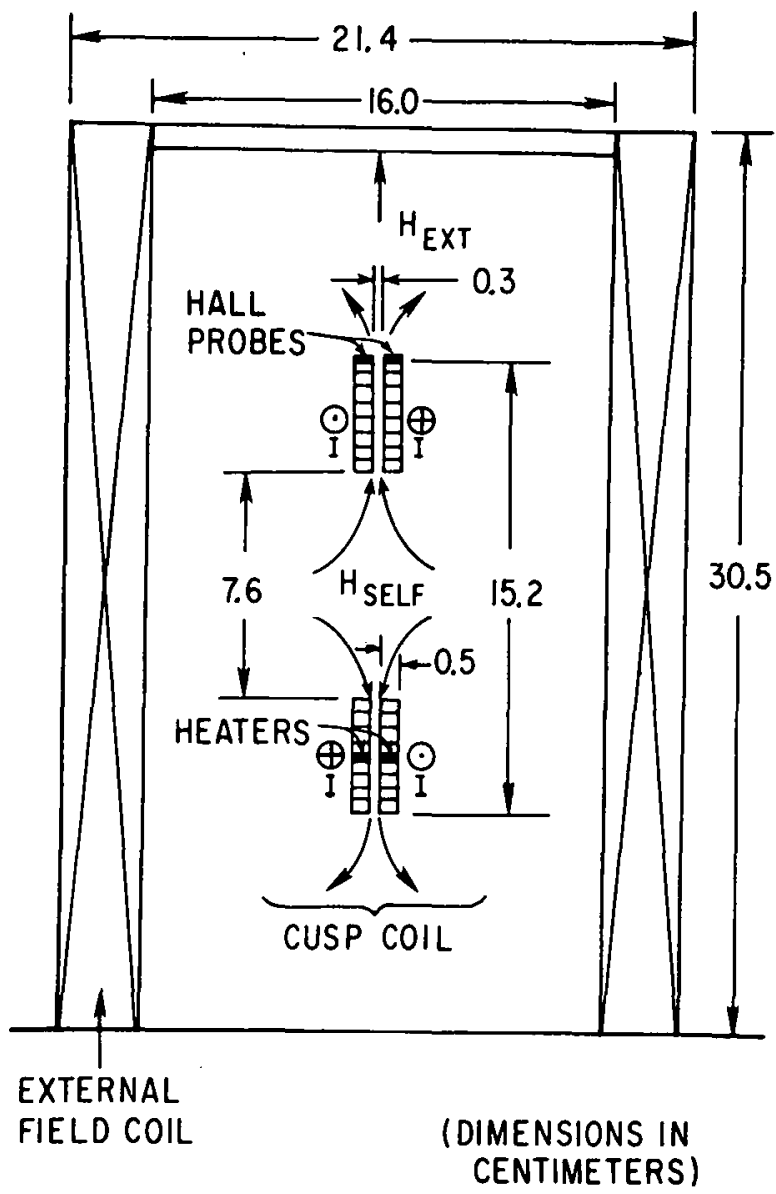

Fig. 4 Cusp Coil Test Experimental Configuration

Three cusp coils were used fú llie tests (Table III). The coils have $50 \%$ of the surface area exposed to the helium bath. Helium is circulated through radial cooling channels. To investigate the effect of cooling channel configuration on cusp coil behavior, the G-10 epoxy-fiberglass conling rhannel discs of coil 4 were replaced by discs with wider cooling channels. The coil was then relabeled $4 \mathrm{~A}$.

\section{TABLE III}

Cusp Coil Properties

\begin{tabular}{|c|c|c|c|c|}
\hline $\begin{array}{l}\text { Cusp Coil } \\
\text { No. }\end{array}$ & $\begin{array}{c}\text { Copper } \\
\text { Thickness } \\
\left(10^{-3} \mathrm{~cm}\right)\end{array}$ & $\begin{array}{c}\text { Cooling } \\
\text { width } \\
(\mathrm{cm})\end{array}$ & $\begin{array}{c}\text { grooves } \\
\text { depth } \\
\text { (cm) }\end{array}$ & Insulation \\
\hline 3 & 15 & 0.64 & 0.079 & $\begin{array}{c}0.0013 \mathrm{~cm} \text { mylar } \\
+\end{array}$ \\
\hline 4. & 25 & 0.64 & 0.079 & $\begin{array}{l}\text { GE7031 varnish } \\
0.0013 \mathrm{~cm} \text { mylar }\end{array}$ \\
\hline $4 \mathrm{~A}$ & 25 & 0.87 & 0.079 & $0.0013 \mathrm{~cm}$ mylar \\
\hline
\end{tabular}

The cusp coil is operated in two modes. The first is a constant voltage mode. For a given current the power supply output voltage is fixed by a $5.9 \mathrm{~m} \Omega$ load resistor. This mode of operation simulates a low inductance, short time constant coil which can reduce its current rapidly following the creation of a normal region. The second mode of operation is a constant current mode with the compliance voltage of the power supply set at its maximum value of 10 volts. In this case, the power supply tries to maintain a constant current through the cusp coll by adjusting its compliance voltage. This simulates a high inductance, long time constant coil which can not reduce its current rapidly upon the creation of a normal region.

Measurements are made in the following two ways. In the first, the cusp coil current is fixed and the external magnetic field $\mathrm{H}_{1}$ is raised at a constant rate (typically $0.03 \mathrm{kOe} / \mathrm{sec}$ ) and returned to zero. During the time that the fleld is ramping up, we monitor the cusp coll to see if a flux jump induced quench occurs. The method is similar to that of Noguchilo.

In the second measurement, both the cusp coil current and external magnetic field are set at some value and the heater current in one of the pancakes is brought up until a thermal runaway occurs in that pancake. Heater current is then decreased to zero. The highest cusp coil current for which complete recovery of superconductivity occurs is defined as the recovery current.

Experimental Results

1. Flux Jumps Figures 5 and 6 show that in both

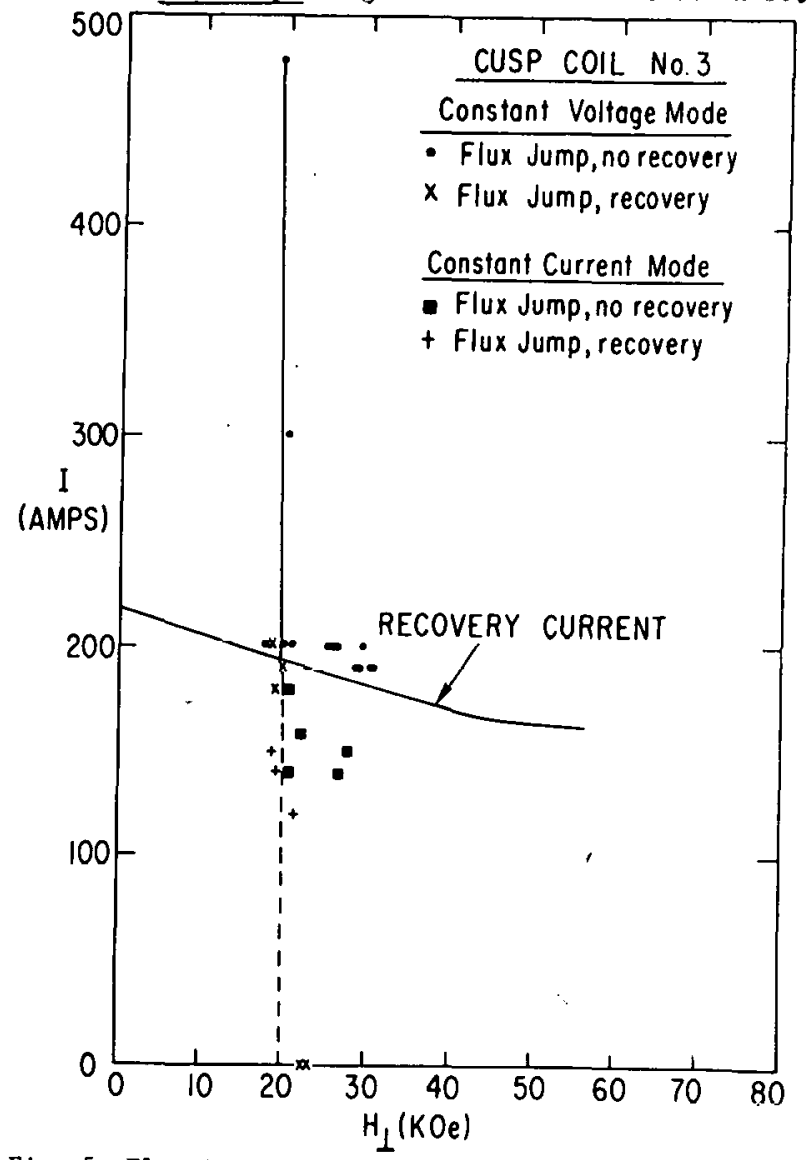

Fig. 5 Flux jump induced quench current vs external magnetic field recovery current for heater induced thernal runaway in constant, voltage mode. 


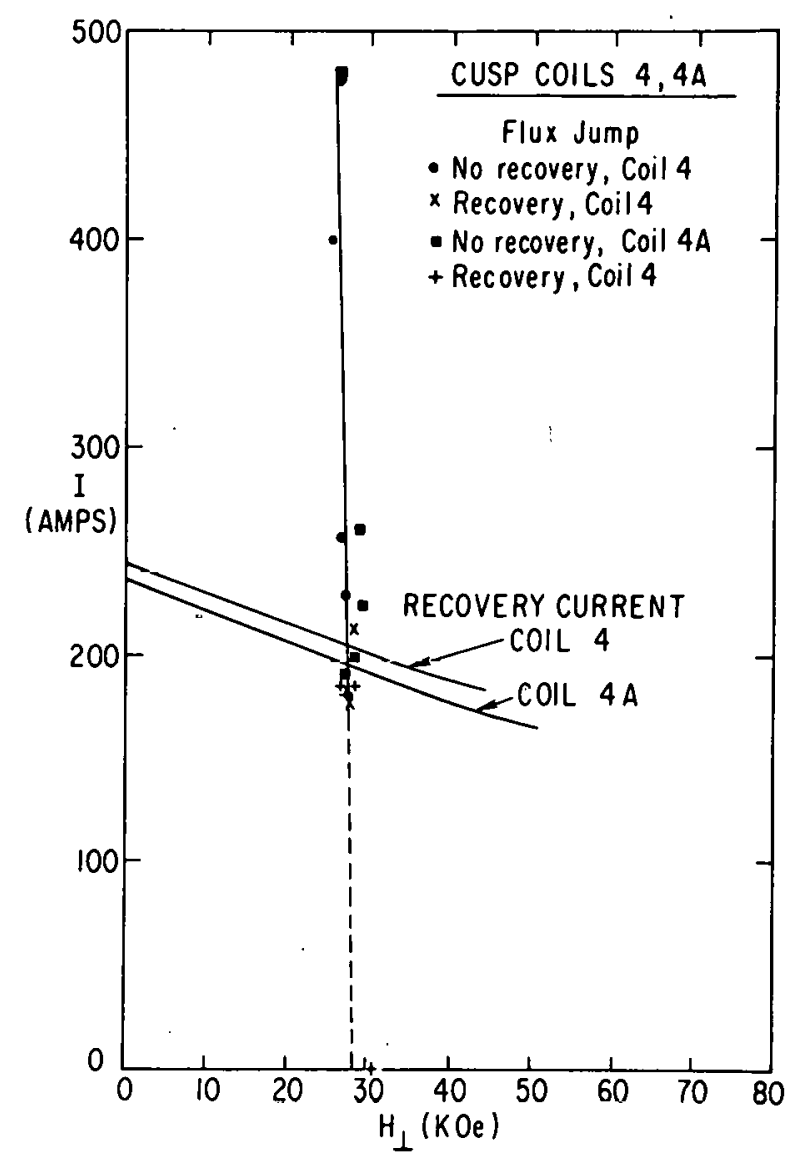

Fig. 6 Flux jump induced quench current vs external magnetic field and recovery current for heater induced thermal runaway, both in constant voltage mode.

the constant voltage and constant current mode of operation a large flux jump occurs in one of the pancakes when the external magnetic field $H_{1}$ reaches a certain value $(20 \mathrm{kOe})$ for cusp coil 3 and $28 \mathrm{kOe}$ for cusp coils 4 and $4 \mathrm{~A}$ ). The occurrence of this large flux jump creates a normal region from which the cusp coil can recover if the cusp coil current is low enough. In some cases one of the pancakes will flux jump and recover whereas the other pancake which transitions at a higher field will not recover. The field value for a first flux jump is the same for both modes of operation.

We compared our results for the flux jump magnetic field $B^{+}$with those of Koyama and Lubell11. They find agreement of theory and experiment at high external magnetic field sweep rates $(\dot{B}=4.35 \mathrm{k0e} / \mathrm{sec})$ using a new theory of dynamic stabilization proposed by Koyama 12 . At low values of $\dot{B}$ they find that agreement is not as good and $B_{f j}(\exp )>B_{f j}$ (theory). For the low $\dot{B}$ rates available $\mathrm{fj}_{\text {with }}$ our apparatus $(0.026-$ $0.066 \mathrm{kOe} / \mathrm{sec})$, the experimental value of $B_{f j}$ was a factor of 2 higher than the calculated one and showed no noticeable dependence on $\dot{B}$.

Comparing the experimental results for cusp coils 3 and 4 shows that $B_{f i}$ does scale roughly with the thickness of stabilizing copper.

2. Recovery Current The cusp coil behavior is quite different for each of the two modes of operacion. In the constant voltage mode, a thermal runaway induced by either a flux jump or heater current immediately produces a fall in cusp coil current and a transition of the pancake into a partially resistive state. ( 0.2 to 0.5 of normal state resistance). Below a threshold value of recovery current, the cusp coil recovers completely once the thermal disturbance is removed.

In the constant current mode, a thermal runaway does not cause the current to fall immediately since the power supply voltage increases to maintain the current. Power generation in the cusp coil is consequently greater for a given current in this mode. At current values comparable to those used during the constant voltage mode, the whole pancake goes normal. For cusp coll 3 no recovery after a heater induced thermal runaway is possible for a current as low as 100 amps. By comparison, the recovery current for the constant voltage mode is around 200 amps.

\section{CONCLUSION}

The $\mathrm{Nb}_{3} \mathrm{Sn}$ ribbon superconductors obtained for a $\mathrm{Nb}_{3} \mathrm{Sn}-\mathrm{NbTi}$ hybrid coil as part of the reduced $\mathrm{D}$ coil test stand can be run in a dynamically stabilized state as long as the perpendicular magnetic fleld component is kept low enough to prevent large flux jumps from occurring. For the two ribbons with the least and most stabilizing copper these fleld values are $20 \mathrm{kOe}$ and $28 \mathrm{kOe}$. One of the ribbons meets the original design criterion for the maximum perpendicular field given in Table II while the other does not. Since the background coils of the reduced $D$ coll test stand will operate at a lower field level than the large test stand, $\quad \mathrm{H}_{1}=25.6 \mathrm{kOe}, \mathrm{H}_{1}=12.5 \mathrm{kOe}$, the ribbons should be flux jump stabte.

\section{REFERENCES}

1. $\Lambda$ Fusion Power Plant, R. G. Mills, ed., Princeton Plasma Physics Laboratory Report iLATT-1050 (1974).

2. UWMAK-I, A Wisconsin Toroidal Fusion Reactor Design University of Wisconsin Report UWFDM (1973)

3. The Jet Project, Preliminary Description, EUR-JETRI (1973).

4. J. File, R. G. Mills, and G. V. Sheffield, Il:EE Transactions on Nuclear Science NS-18, 277 (1.971).

5. V. D. Shafranov, Soviet Physics-Technical Physics 17, 1433 (1973).

6. J. File and G. V: Sheffield, Proceedings of the . Fourth International Conference on Magnet Technology (National Technical Information Service, Springfield, Va., 1972) Conf. 720908, pp. 240-251.

7. J. File and J. H. Willard, Proceedings of the Fifth Symposium on Engineering Probletns of Fusion Research (Institute of Electrical and Electronics Engineers, New York, 1974) pp. 592-596.

8. J. W. Willard and C. D. Martin, Advances in Cryogenic Engineering (Plenum Press, New York, 1973). Vol. 18, pp. 382-387.

9. D. L. Coffey, W. F. Gauster, and M. S. Lubei1, J. App1. Phys. 42, 59 (1971).

10. T. Noguchi, Proceedings of the Fourth International Conference on Magnet Technology (National Technical Information Service, Springfield, Va. 1972) Conf. 720908, pp. 529-536.

11. K. Koyama and M. S. Lubell, Oak Ridge National Laboratory Report TM-4391.

12. K. Koyama, J. Appl. Phys. 44, 5531 (1973). 
LEGAL NOTI C E-

This report was prepared as an account of Government sponsored work. Neither the United States, nor the Commission, nor any person acting on behalf of the Commission:

A. Makes any warranty or representation, express or implied, with respect to the accuracy, completeness, or usefulness of the information contained in this report, or that the use of any information, apparatus, method, or process disclosed in this report may not infringe privately owned rights; or

B. Assumes any liabilities with respect to the use of, or for damages resulting from the use of any information, apparatus, method, or process disclosed in this report.

As used in the above, "person acting on behalf of the Commission" includes any employee or contractor of the Commission to the extent that such employee or contractor prepares, handles or distributes, or provides access to, any information pursuant to his employment or contraot with the Commissinn. 